\title{
Activating Peroxymonosulfate Using Carbon from Cyanobacteria as Support for Zero-Valent Iron
}

\author{
Hefei University \\ Layun Zhu \\ Hefei University \\ Sisi Cao \\ Hefei University \\ Zhaoming Chen \\ Hefei University \\ Zihui Song \\ Hefei University \\ Xiaohong Yang \\ Hefei University \\ Jie Jin \\ Hefei University
}

Jun Chen ( $\nabla$ chenjun@hfuu.edu.cn )

\section{Research Article}

Keywords: Cyanobacterial carbon, NZVI@ACC, PMS activation

Posted Date: January 18th, 2022

DOI: https://doi.org/10.21203/rs.3.rs-1042547/v1

License: (c) (i) This work is licensed under a Creative Commons Attribution 4.0 International License.

Read Full License 
1 Activating Peroxymonosulfate using Carbon from Cyanobacteria as

\section{Jun Chen ${ }^{\mathrm{a}, \mathrm{b}}$}

4 Corresponding author. Tel.: +86 551 62158405; Fax: +86 55162158406.

5 E-mail: chenjun@hfuu.edu.cn

$6 \quad{ }^{a}$ School of Biology, Food and Environment, Hefei University, Hefei 230601, P. R. China.

$7{ }^{b}$ Anhui Key Laboratory of Sewage Purification and Eco-restoration Materials, Hefei 230088, P.

8 R. China.

9 Layun $\mathbf{Z h u}^{\mathrm{a}, \mathrm{b}}$

$10{ }^{a}$ School of Biology, Food and Environment, Hefei University, Hefei 230601, P. R. China.

$11{ }^{b}$ Anhui Key Laboratory of Sewage Purification and Eco-restoration Materials, Hefei 230088, P.

12 R. China.

13 Sisi Cao ${ }^{\mathrm{a}, \mathrm{b}}$

$14{ }^{a}$ School of Biology, Food and Environment, Hefei University, Hefei 230601, P. R. China.

$15{ }^{b}$ Anhui Key Laboratory of Sewage Purification and Eco-restoration Materials, Hefei 230088, P. 16 R. China.

\section{Zhaoming Chen ${ }^{\mathrm{a}, \mathrm{b}}$}

$18{ }^{a}$ School of Biology, Food and Environment, Hefei University, Hefei 230601, P. R. China.

$19{ }^{b}$ Anhui Key Laboratory of Sewage Purification and Eco-restoration Materials, Hefei 230088, P.

20 R. China.

\section{Zihui Song ${ }^{\mathrm{a}, \mathrm{b}}$}

$22{ }^{a}$ School of Biology, Food and Environment, Hefei University, Hefei 230601, P. R. China.

$23{ }^{b}$ Anhui Key Laboratory of Sewage Purification and Eco-restoration Materials, Hefei 230088, P.

24 R. China.

25 Xiaohong Yang ${ }^{\mathrm{a}, \mathrm{b}}$

$26{ }^{a}$ School of Biology, Food and Environment, Hefei University, Hefei 230601, P. R. China.

$27{ }^{b}$ Anhui Key Laboratory of Sewage Purification and Eco-restoration Materials, Hefei 230088, P.

28 R. China.

29 Jie Jin ${ }^{\mathrm{a}, \mathrm{b}}$

$30{ }^{a}$ School of Biology, Food and Environment, Hefei University, Hefei 230601, P. R. China.

$31{ }^{b}$ Anhui Key Laboratory of Sewage Purification and Eco-restoration Materials, Hefei 230088, P.

32 R. China.

33 
Activating Peroxymonosulfate using Carbon from Cyanobacteria as

\section{Support for Zero-valent Iron}

38 Jun Chen ${ }^{\mathrm{a}, \mathrm{b} *}$, Layun $\mathrm{Zhu}^{\mathrm{a}, \mathrm{b}}$, Sisi Cao ${ }^{\mathrm{a}, \mathrm{b}}$, Zhaoming Chen ${ }^{\mathrm{a}, \mathrm{b}}$, Zihui Song ${ }^{\mathrm{a}, \mathrm{b}}$, Xiaohong

39 Yang $^{\mathrm{a}, \mathrm{b}}$, Jie Jin ${ }^{\mathrm{a}, \mathrm{b}}$

$40{ }^{a}$ School of Biology, Food and Environment, Hefei University, Hefei 230601, P. R. China.

$41{ }^{b}$ Anhui Key Laboratory of Sewage Purification and Eco-restoration Materials, Hefei 230088, P.

42 R. China.

43

44

45

46

47

48

49

\section{Abstract}

In the present study, the cyanobacterial char (ACC) prepared from Chaohu cyanobacteria was used as a nanoscale carrier for zero-valent iron (NZVI) to synthesize a highly efficient activation material designated as cyanobacterial charsupported nanoscale zero-valent iron (NZVI@ACC), which was subsequently used for activating peroxymonosulfate (PMS) to degrade the orange II (OII) dye. The XRD and XPS results revealed that NZVI was anchored onto the ACC through coordination bonding, thereby forming a stable structure. The SEM and TEM observations revealed that the NZVI was embedded in the sheet structure of the ACC. The NZVI@ACC had a larger specific surface area $\left(42.249 \mathrm{~m}^{2} / \mathrm{g}\right)$, and also magnetism, due to which its components could be separated through an externally applied magnetic field. Using this NZVI@ACC/PMS system, the rate of degradation of OII (100 mg/L) reached $98.32 \%$ within $14 \mathrm{~min}$. The OII degradation reaction using the NZVI@ACC/PMS system followed first-order kinetics. The activation energy of this degradation reaction was $17.34 \mathrm{~kJ} /(\mathrm{mol} \cdot \mathrm{K})$. Quenching and EPR experiments revealed that both $\mathrm{SO}_{4} \cdot{ }^{-}$and $\cdot \mathrm{OH}$ were produced in this reaction, with $\mathrm{SO}_{4} \cdot{ }^{-}$playing the major role in the reaction. The theoretical calculations revealed that $\mathrm{SO}_{4} \cdot^{-}$attacked the $12(\mathrm{~N})$ of OII, which destroyed and degraded the structure of OII. The presence of halogen ions in the actual dye-containing wastewater samples inhibited the OII degradation by the NZVI@ACC system to different degrees, and the inhibition effect followed the order: $\mathrm{I}^{-}>\mathrm{Br}^{-}>\mathrm{Cl}^{-}$.

Keywords: Cyanobacterial carbon; NZVI@ACC; PMS activation

\footnotetext{
* Corresponding author. Tel.: +86 551 62158405; Fax: +86 55162158406.

E-mail: chenjun@hfuu.edu.cn
} 


\section{Introduction}

Advanced oxidation processes (AOPs) based on sulfate radicals are gaining increasing attention recently. In comparison to the hydroxyl radical $(\cdot \mathrm{OH})$-based advanced oxidation, the sulfate radical $\left(\mathrm{SO}_{4}{ }^{-}\right)$-based AOPs have a higher redox potential $(2.5 \sim 3.1 \mathrm{~V})$ and a longer half-life $\left[\mathrm{T}_{1 / 2}\left(\mathrm{SO}_{4}{ }^{-}\right)=30 \sim 40 \mu \mathrm{s} ; \mathrm{T}_{1 / 2}(\cdot \mathrm{OH})=10^{-}\right.$ $\left.{ }^{3} \mu \mathrm{s}\right]$, which becomes a contributing factor in the effective and sustainable degradation of refractory organic matter in water (Yang, et al.2011; Sun, et al. 2019). In a typical AOP, peroxymonosulfate (PMS) may be activated to generate $\mathrm{SO}_{4} \cdot^{-}$using various activation methods, including those based on the ultraviolet light, electricity, heat, alkali, and transition metal ions such as $\mathrm{Cu}^{2+}, \mathrm{Co}^{2+}, \mathrm{Fe}^{2+}$, etc. (Wang, et al., 2017; Sun, et al., 2017; Xu, et al., 2020). Light-based and thermal activation methods are expensive and energy-consuming, rendering it difficult to achieve effective PMS activation in dark and low-temperature environments. Moreover, the commonly available transition metals, such as $\mathrm{Ag}^{+}, \mathrm{Co}^{2+}$, and $\mathrm{Cu}^{2+}$, are biotoxic and prone to secondary pollution (Zha, et al., 2016; Czech, et al., 2015; Soubh, A., \& Mokhtarani, N. et al., 2016; Lin, Liang, Chen, et al., 2011).

Nanoscale zero-valent iron (NZVI), reduced iron powder, and other kinds of NZVI have been used for catalyzing the PMS degradation of organic pollutants in the environment. The term NZVI refers to the particles with sizes ranging from 1 to 100 $\mathrm{nm}$, large specific surface area, and strong reducibility, properties that confer NZVI with high reactivity and excellent adsorption performance. However, the small size and the high reactivity of these nanoparticles leads to easy agglomeration, poor dispersion, and no ideal reactivity, all of which seriously impact their performance during the actual usage ( $\mathrm{Li}$, et al., 2019; Yan, et al., 2015). Therefore, various methods for preventing agglomeration during practical application have been studied, including the addition of a dispersant or carrier to the reaction system to disperse the nanoparticles as they are synthesized (Zhong, et al., 2019; Song, et al., 2015).

With environment-friendly materials receiving increasing attention in the past few years, environment-friendly carrier materials and biochar exhibiting ideal immobilization and several economic and environmental advantages have gradually emerged (Wu, et al., 2018; Lee, Gunten, Kim, 2020; Zhou, et al., 2014; Kwon, et al., 2015). The phenomenon of eutrophication in several water bodies has caused cyanobacteria to accumulate and occupy a large area of the water surface, leading to a 
series of ecological and environmental problems, including infringing on livestock, fish, and humans, and directly inducing liver cancer. The domestic measures for cyanobacteria control are implemented mostly after the outbreak of water blooms. The commonly used emergency control measures include salvage and ashore treatment and disposal by manpower, ships, tools, or other physical methods. However, disposal of algae sludge does not happen in time, thereby leading to various environmental problems that are being now being focused on by the management departments and all sectors of human society. Cyanobacteria are characterized by low ash, high moisture, and high volatility, with levels of $\mathrm{C}, \mathrm{H}, \mathrm{O}$, fixed carbon, and volatility similar to those in rice straw and tung wood. These characteristics of cyanobacteria allow their application in synthesizing materials with developed pore structures (Zhang, et al., 2020; Gong, et al., 2017).

$$
\text { Meanwhile, researchers are also attempting to design and modify biochar using }
$$
various physical and chemical methods to further improve its performance. Since different modification methods have different effects on biochar, it is particularly important to improve the characteristics of biochar specific to the requirements (Lian, et al., 2020; Ma, et al., 2018; Liu, et al., 2018).

In the present study, cyanobacterial char (ACC) supported nanoscale zero-valent iron (NZVI@ACC) was prepared and then used for activating PMS to achieve the removal of a typical refractory organic dye named OII from water samples. The study included the following aspects: (1) characterization of the prepared NZVI@ACC, (2) evaluation of the factors associated with the NZVI@ACC/PMS system influencing the OII degradation, (3) determination of the active species of the reaction system and analyzing the underlying activation mechanism, and (4) explore the effect of the NZVI@ACC/PMS system on different halogens and dyes.

\section{Materials and Methods}

\subsection{Materials}

Cyanobacteria collected from Chaohu lake were used as the raw material for obtaining biochar. PMS ( $\left.\mathrm{KHSO}_{5} \cdot 0.5 \mathrm{KHSO}_{4} \cdot 0.5 \mathrm{~K}_{2} \mathrm{SO}_{4}\right), \mathrm{FeSO}_{4} \cdot 7 \mathrm{H}_{2} \mathrm{O}, \mathrm{NaBH}_{4}, \mathrm{HCl}$, $\mathrm{NaOH}, \mathrm{C}_{2} \mathrm{H}_{6} \mathrm{O}, \mathrm{CH}_{3} \mathrm{OH},\left(\mathrm{CH}_{3}\right)_{3} \mathrm{COH}, \mathrm{CH}_{4} \mathrm{O}(\mathrm{MeOH})$, and $\mathrm{C}_{4} \mathrm{H}_{10} \mathrm{O}$ (TBA) were purchased from Aladdin Reagent Co. Ltd. Congo red $\left(\mathrm{C}_{32} \mathrm{H}_{22} \mathrm{~N}_{6} \mathrm{Na}_{2} \mathrm{O}_{6} \mathrm{~S}_{2}, \mathrm{CR}\right)$, methylene blue $\left(\mathrm{C}_{18} \mathrm{H}_{22} \mathrm{ClN}_{3} \mathrm{~S}, \mathrm{MB}\right)$, and rhodamine $\mathrm{B}\left(\mathrm{C}_{28} \mathrm{H}_{31} \mathrm{ClN}_{2} \mathrm{O}_{3}, \mathrm{RB}\right)$ were 
131 purchased from Sinopharm Chemical Reagent Co. Ltd. All reagents used in the 132 present study were of analytical grade.

\section{$133 \quad 2.2$ Preparation of NZVI@ACC}

134 An appropriate amount of dry cyanobacteria powder was placed in a crucible. The 135 tube furnace was programmed to heat at $500{ }^{\circ} \mathrm{C}$ for $6 \mathrm{~h}$ at a heating rate of $10{ }^{\circ} \mathrm{C} / \mathrm{min}$ 136 under $\mathrm{N}_{2}$ protection. The carbonization temperature was maintained for the stated 137 duration and then the furnace was cooled. The carbonized powder was ground 138 through a 100 -mesh sieve and then soaked in $1 \mathrm{~mol} / \mathrm{L}$ of $\mathrm{HCl}$ for $12 \mathrm{~h}$. After the 139 removal of ash, the powder was washed with deionized water, neutral dried, and 140 preserved. An amount of $3.754 \mathrm{~g}$ of $\mathrm{FeSO}_{4} \cdot 7 \mathrm{H}_{2} \mathrm{O}$ was dissolved in $250 \mathrm{~mL}$ deionized 141 water $(0.054 \mathrm{~mol} / \mathrm{L})$ followed by the addition of $250 \mathrm{~mL}$ of anhydrous ethanol as the 142 dispersant. ACC was added to this solution followed by magnetic stirring ( $200 \mathrm{r} / \mathrm{min}$ ) 143 for $10 \mathrm{~h}$. The solution was then dried and ground, and the obtained dry mixture was 144 dissolved in $100 \mathrm{~mL}$ of deoxidized and deionized water to obtain a solution. 145 Subsequently, intermediate products and $50 \mathrm{~mL}(1 \sim 2$ drops/s $)$ of $0.135 \mathrm{~mol} / \mathrm{L}$ of 146 freshly prepared $\mathrm{NaBH}_{4}$ solution were added to this solution under the protection of 147 nitrogen. After aging for $1 \mathrm{~h}$, black particles were generated, which were first washed 148 three times with deoxidized and deionized water three times and then with ethanol. 149 Finally, after vacuum drying in an oven, NZVI@ACC was obtained and stored in a 150 sealed container for preservation.

\section{$151 \quad 2.3$ Experimental procedure}

152 The batch test was performed in a glass conical flask $(250 \mathrm{~mL})$ containing $100 \mathrm{~mL}$ 153 of the reaction solution. NZVI@ACC was added to $100 \mathrm{~mL}$ of OII $(100 \mathrm{mg} / \mathrm{L})$ at the 154 initial $\mathrm{pH}$ of 6 . Subsequently, the flask was placed in an oscillation box at a constant 155 temperature of $25^{\circ} \mathrm{C}$ and an oscillation frequency of 110 times/min. PMS ( $\left.1 \mathrm{mmol} / \mathrm{L}\right)$ 156 was added and the duration was measured after dissolution. The effects of the 157 following parameters on the degradation of OII were studied: the dosage of 158 NZVI@ACC, the ratio of carbon to iron in NZVI@ACC, the reaction temperature, 159 and the reaction $\mathrm{pH}$. At each measurement time point, a volume of $5 \mathrm{~mL}$ was sampled 160 and filtered through a $0.45 \mu \mathrm{m}$ filter membrane. The absorbance of the filtered sample 161 was measured at $484 \mathrm{~nm}$ in an ultraviolet spectrophotometer.

\section{$162 \quad 2.4$ Analytical methods}


163

164

165

166

167

168

169

170

171

172

173

174

175

176

177

178

179

180

181

182

183

184

185

186

187

188

189

190

191

192

193

194

TD-3500 X-ray diffractometer (Dandong Tongda) was employed to radiate the samples to obtain their X-ray diffraction (XRD) patterns. The XPS spectra were obtained by scanning the samples using Thermo Fisher K-Alpha X-ray photoelectron spectroscopic instrument (Thermo Field). In addition, the samples were gold-plated and observed under an S-4800 cold-field emission scanning electron microscope (Hitachi Company, Japan). Transmission electron microscopy (TEM) observation of the samples was performed using FEI-TALOS-F200X. The free radicals in the samples were detected using electron paramagnetic resonance (EPR, Bruker A300, Germany). A vibrating sample magnetometer (VSM) was used at $7040 \pm 2 \mathrm{~T}$ (Lake Shore, American). The specific surface area and the pore size of the particles in the sample were determined based on the nitrogen adsorption/desorption curves using a fully automated surface and porosity tester (Quantachrome, USA).

\section{Results and Discussion}

\subsection{Material characterization}

\subsubsection{XRD and XPS analyses}

The XRD pattern and the results of the XPS survey, and XPS analysis of C 1s, O 1s, and Fe 2p binding states in NZVI@ACC were depicted in Fig. 1. A sharp diffraction peak was observed at $44.7^{\circ}$, as depicted in Fig. (a), while a weak diffraction peak was observed at $64.8^{\circ}$. When compared to the standard PDF card (06-0696) of iron, these two peaks corresponded precisely to the 110 crystal plane diffraction $\left(44.7^{\circ}\right)$ and 200 crystal plane diffraction $\left(65.0^{\circ}\right)$, respectively. According to Bragg's equation, the crystal spacing was $0.203 \mathrm{~nm}$. The chemical composition of NZVI@ACC was revealed in the XPS analysis and was presented in Fig. 1 (b)-(e). The binding energies of $\mathrm{C} 1 \mathrm{~s}$ at $284.7 \mathrm{eV}$ and $286.0 \mathrm{eV}$ were classified as those of $\mathrm{C}-\mathrm{C}$ and $\mathrm{C}-\mathrm{O}$, respectively. In the $\mathrm{Fe} 2 \mathrm{p}$ spectra, the binding energy of the characteristic peaks at $707.00 \mathrm{eV}, 710.70 \mathrm{eV}$, and $712.50 \mathrm{eV}$ were attributed to $\mathrm{Fe}^{0}, \mathrm{Fe}^{2+}$, and $\mathrm{Fe}^{3+}$, respectively (Li, et al., 2019 ). After loading the NZVI onto NZVI@ACC, the Fe peak [peak $\mathrm{C}$ depicted in Fig. 1 (c)] was formed at $288.7 \mathrm{eV}$, while the characteristic peak of C-O exhibited a redshift [Fig. 1 (d)] indicating the loss of electrons of $\mathrm{C}$ and $\mathrm{O}$ corresponding to the gain of electrons of Fe. According to the hybrid orbital theory, it may be observed in Fig. 1(f), (g), and (h) that the lone pair electrons from $\mathrm{C}$ sp3 and O sp3 hybrid orbital could occupy the $\mathrm{Fe}^{2+} \mathrm{sp} 3 \mathrm{~d} 2$ orbital, which suggests that a 
195 coordinate bond (Fe-C and Fe-O) could be established between the NZVI and the 196 active group on the surface of ACC.

\subsubsection{SEM and TEM}

The morphology of the catalysts was observed using SEM and TEM. As depicted in Fig. 2, the NZVI@ACC material had a loose structure and a flat lamellar organization, which was attributed to the aggregation of NZVI during its formation process. The TEM images were depicted in Fig. 2 (c, d). The TEM results revealed that the iron particles (black spots in the depicted images) were highly dispersed throughout ACC. The lattice spacing was determined to be $0.203 \mathrm{~nm}$ and the crystal plane was (110). The images depicted in Fig. 2 (e, f) together confirmed the successful preparation of NZVI@ACC with an even distribution of NZVI over the ACC surface. However, although the prepared NZVI@ ACC had an increased surface area, it also contained an increased number of edges and defects.

\subsubsection{BET and Magnetic detection}

The Brunauer-Emmett-Teller (BET) surface area $\left(\mathrm{S}_{\mathrm{BET}}\right)$ and the pore volume of NZVI@ACC, determined according to the $\mathrm{N}_{2}$ adsorption-desorption isotherm, and BJH desorption pore size distribution were $49.249 \mathrm{~m}^{2} / \mathrm{g}$ and $0.104 \mathrm{~cm}^{2} / \mathrm{g}$, respectively

212 [Fig. 3 (a)]. According to the IUPAC classification, the adsorption isotherms of 213 NZVI@ACC were of the characteristic type IV, with $\mathrm{P} / \mathrm{P}_{0}$ having an $\mathrm{H} 4$ hysteresis 214 loop between 0.4 and 1.0. The prepared NZVI@ACC contained both micropores and 215 mesoporous pores, most with sizes of approximately $19.096 \mathrm{~nm}$.

Fig. 3 (b) depicted the hysteresis loop of NZVI@ACC. The symmetric loop shape of the origin indicated good ferromagnetism and sub-ferromagnetism of the prepared NZVI@ACC, due to which its components could be separated using an external magnetic field during a practical application thereby allowing material recycling. This was also verified in experimental operation. The coercivity and magnetization of

221 NZVI@ACC were 233.16 Oe and $0.67 \mathrm{emu} / \mathrm{g}$, respectively. The low saturation 222 magnetization of NZVI@ACC indicated that the particle size of NZVI@ACC was in 223 the micron range, which was consistent with the SEM results.

\subsection{Effects of reaction conditions on OII degradation}

225 The effects of activator dosage, Fe/C ratio, reaction temperature, and reaction $\mathrm{pH}$ 226 on the activation of PMS using NZVI@ACC were analyzed. The results were 227 presented in Fig. 4. 
The effects of different dosages of activator on the degradation of OII were presented in Fig. 4 (a) and Fig. 4 (e). Since NZVI@ ACC provided the active sites, its dosage affected the degradation effect of OII. PMS had a high redox potential (2.01 V), and due to its low activity, the rate of OII removal could only reach $4.62 \%$ within 14 min. When $0.1 \mathrm{~g}$ of NZVI@ACC was added to the system, the rate of OII removal reached $98.32 \%$ within 14 min. With the increase in the dosage of NZVI, the oxygencontaining functional groups on the surface of NZVI@ACC also increased, thereby increasing the activation of PMS (Li, et al., 2016). The simulation results presented in Fig. 4 (e) revealed that the reaction process conformed to first-order kinetics under the influence of dosage. Within a certain range, both kinetic constant $\mathrm{k}$ and the reaction rate increased. According to origin fitting analysis, the reaction rate constant increased linearly with increasing dosage, which was consistent with $\mathrm{y}=2.89 \mathrm{x}-$ 0.0108; the correlation index $\mathrm{R}^{2}$ was 0.973 . As the dosage increased, a greater NZVI@ACC surface area was available for the reaction, which increased the reaction rate. However, when the activator was in excess, no significant change was observed in the effect of OII removal as the excessive activator led to wasted active sites and decreased utilization rate of the material.

As visible in Fig. 4 (b), ACC had almost no catalytic effect on PMS, and the rate of OII removal achieved using the ACC/PMS system was only $9.43 \%$ within 14 min. After the addition of NZVI, which was a strong reducing agent, to the system, the OII removal effect of the system was significantly improved. When the ratio of carbon to iron in the NZVI@ACC/PMS system was 1:1, the OII removal rate reached 98.32\% within 14 min, which was almost complete removal. The NZVI@ACC/PMS system, therefore, exhibited the best OII removal effect.

The influence of reaction temperature on the OII degradation effect was depicted in 254 degradation rate of $93.09 \%$ was reached within $14 \mathrm{~min}$. When the reaction 255 temperature was increased to $25^{\circ} \mathrm{C}$ and $40{ }^{\circ} \mathrm{C}$, the OII removal rate increased to over $25698.32 \%$. It could be observed that within a certain range, an increase in the reaction 257 temperature could accelerate the molecular movement and improve the reaction speed. 258 Fig. 4 (f) illustrated the kinetic simulation of the OII degradation effects at different 259 temperatures, which conformed to quasi-first-order kinetics. The degradation rate 260 increased with the increase in the reaction temperature from $10{ }^{\circ} \mathrm{C}$ to $40{ }^{\circ} \mathrm{C}$. The 
increase in the temperature increased the energy absorbed by the molecules during the reaction and accelerated the decomposition to produce free radicals (Zrinyi, Pham, 2017). Meanwhile, the molecular motion was accelerated, which increased the probability and the rate of molecular collision, thereby accelerating the reaction process (Hori, et al., 2005). According to the Arrhenius' law, the relationship between the reaction rate and the temperature followed the equation $\operatorname{lnk}=\ln \mathrm{A}-\mathrm{E}_{\mathrm{a}} / \mathrm{RT}$. After linear fitting lnk and 1/T, the following fitting equation was obtained: $\mathrm{Y}=-2086.2 \mathrm{x}+$ 5.7156, and the activation energy of NZVI@ACC-activated PMS-based degradation of OII was calculated to be $17.34 \mathrm{~kJ} /(\mathrm{mol} \cdot \mathrm{K})$.

Furthermore, the $\mathrm{pH}$ of the reaction system affects the free radicals in the system, which, in turn, has a significant influence on the PMS-based degradation of pollutants in wastewater. The results presented in Fig. 4 (d) revealed that at the initial reaction $\mathrm{pH}$ of 4 , the OII removal rate was $99.01 \%$ within 14 min. At the $\mathrm{pH}$ of 6 and 8 , the OII removal rates were $98.32 \%$ and $93.09 \%$, respectively. Therefore, while a high degradation rate was maintained, the degradation rates were different at different $\mathrm{pH}$ values. In a weakly acidic environment, NZVI@ACC was more likely to precipitate $\mathrm{Fe}^{2+}, \mathrm{SO}_{4}{ }^{2-}, \cdot \mathrm{OH}$, and $\mathrm{Fe}^{3+}$ produced upon the activation of PMS by $\mathrm{Fe}^{2+}$ (equation 1 and 2), thereby generating more $\cdot \mathrm{OH}$ as $\mathrm{SO}_{4} \cdot{ }^{-}$captured an electron from $\mathrm{H}_{2} \mathrm{O}$ (equation 3) (Du, et al., 2016; Fuller, et al., 2013; Hussain, et al., 2017; Lin, et al., 2013). However, in alkaline conditions, $\mathrm{SO}_{4}{ }^{-}$and $\mathrm{OH}^{-}$could generate $\cdot \mathrm{OH}$ with a slightly lower oxidation activity (equation 4), thereby decelerating the degradation rate, although the organic compounds could nonetheless be degraded by $\cdot \mathrm{OH}$ ultimately. When the $\mathrm{pH}$ increased to 10 , the OII degradation rate of only $67.55 \%$ remained. With the increase of $\mathrm{pH}$, a passivation layer was formed on the surface of NZVI, which inhibited the generation of free radicals, thereby decreasing the OII degradation rate (Gao, et al., 2019; Zhang, et al., 2020).

$$
\begin{aligned}
& \mathrm{Fe}^{2+}+\mathrm{HSO}_{5}^{-} \rightarrow \mathrm{Fe}^{3+}+\mathrm{OH}+\mathrm{SO}_{4}{ }^{2-} \\
& \mathrm{Fe}^{2+}+\mathrm{HSO}_{5}^{-} \rightarrow \mathrm{Fe}^{3+}+\mathrm{HO}^{-}+\mathrm{SO}_{4} \cdot \\
& \mathrm{SO}_{4}{ }^{-}+\mathrm{H}_{2} \mathrm{O} \rightarrow \mathrm{SO}_{4}^{2-}+\mathrm{OH}+\mathrm{H}^{+} \\
& \mathrm{SO}_{4} \cdot{ }^{-}+\mathrm{OH}^{-} \rightarrow \mathrm{SO}_{4}{ }^{2-}+\mathrm{OH}
\end{aligned}
$$

\subsection{Mechanism underlying the effect of OII degradation by NZVI@ACC-} activated PMS 
$\mathrm{MeOH}$ reacts rapidly with both $\mathrm{SO}_{4} \cdot^{-}\left(9.7 \times 10^{8} \mathrm{~L} / \mathrm{mol} \cdot \mathrm{s}\right)$ and $\cdot \mathrm{OH}\left(3.2 \times 10^{6}\right.$

$294 \mathrm{~L} / \mathrm{mol} \cdot \mathrm{s}$ ) (Huang, et al., 2014), TBA is well-recognized efficient scavenger of $\cdot \mathrm{OH}$ that is not sensitive to $\mathrm{SO}_{4} \cdot{ }^{-}$because of its higher reaction rate constant for $\cdot \mathrm{OH}(3.8 \sim$ $\left.7.6 \times 10^{8} \mathrm{~L} / \mathrm{mol} \cdot \mathrm{s}\right)$ compared to that for $\mathrm{SO}_{4} \cdot^{-}\left(4.0 \sim 9.1 \times 10^{5} \mathrm{~L} / \mathrm{mol} \cdot \mathrm{s}\right)$. Therefore, TBA serves as the probe specifically for · OH (Pham, Suto, Inoue, 2009; Tsai, et al., 2008; Anipsitakis, Dionysiou, 2004). The free radical inhibitors $\mathrm{MeOH}$ and TBA were utilized to determine the contribution of $\mathrm{SO}_{4}{ }^{-}$and $\cdot \mathrm{OH}$ in the reaction process. The results of the analysis were presented in Fig. 5 (a). An OII degradation rate of $98.32 \%$ was achieved in the no scavenger group, which decreased to $74.54 \%$ and $84.49 \%$ after the addition of $\mathrm{MeOH}$ and $\mathrm{TBA}$, respectively. $\mathrm{MeOH}$ exhibited a greater inhibition effect compared to TBA, based on which it was speculated that $\mathrm{SO}_{4} \cdot{ }^{-}$played a major role in the reaction. The free radicals generated in the NZVI@ACC/PMS system remained concentrated on the surface of the activator and, therefore, the reaction occurred on the surface of the activator (Dong, et al., 2019).

In order to determine the types of active free radicals generated in the reaction process, the trapping agent DMPO was used for EPR detection during the degradation process. The results were presented in Fig. 5 (b). No evident signal peak appeared for the reaction system with only PMS, and the degradation rate achieved was only 4.62\% without NZVI@ACC, which indicated that PMS was relatively stable and no active free radicals were generated in the system. In the DMPO capture results for the NZVI@ACC/PMS system, the characteristic peaks of DMPO-OH at 1:2:2:1 and DMPO-SO $\mathrm{S}_{4}$ at 1:1:1:1:1 were detected within 2 min, indicating the presence of $\cdot \mathrm{OH}$ and $\mathrm{SO}_{4} \cdot^{-}$in the reaction system.

Theoretical calculations were performed to provide deeper insights into the OII degradation by NZVI@ACC activated PMS. Numerous free radicals were generated in the NZVI@ACC/PMS reaction system. The main types of reactions possible were the free radical reactions and the nucleophilic reactions. The calculations for the local descriptor and Fukui function were performed to identify the most vulnerable sites of OII. The optimized OII molecule is depicted in Fig. 6. The CDD values calculated using Gaussian 09 were listed in Table 1. The highest CDD value of $12(\mathrm{~N})$ atom indicated that $12(\mathrm{~N})$ was the site most vulnerable to the attack of oxidative species.

324 The proposed degradation mechanism underlying the reaction for OII degradation by 325 NZVI@ACC/PMS was presented in Fig. 7. First, there reacted a contact among OII, 
NZVI@ACC, and PMS, and the reaction happened under the action of agitation. Next,

327 the free radicals produced in the reaction attack the $12(\mathrm{~N})$, thereby breaking down the OII structure and producing smaller organic molecules, such as phenyl amine, naphthalene, etc. Finally, OII was degraded completely into small molecules $\left(\mathrm{CO}_{2}\right.$ and $\mathrm{H}_{2} \mathrm{O}$ ) (Yin, et al., 2017).

\subsection{Applications}

Halogen ions are the common anions present in dye wastewater and may react with $\mathrm{SO}_{4}{ }^{-}$and $\cdot \mathrm{OH}$ (Zhang, Parker, 2018) according to the following reaction formula:

$$
\mathrm{SO}_{4} \cdot \% \cdot \mathrm{OH}+\mathrm{X}^{-} \rightarrow \mathrm{SO}_{4}^{2-}+\mathrm{OH}^{-}+\mathrm{X}
$$

Here, $\mathrm{X}$ denotes the halogen ion, such as $\mathrm{Cl}^{-}, \mathrm{Br}^{-}$, and $\mathrm{I}^{-}$.

According to the steady-state approximation, the degradation rate of OII may be expressed as follows:

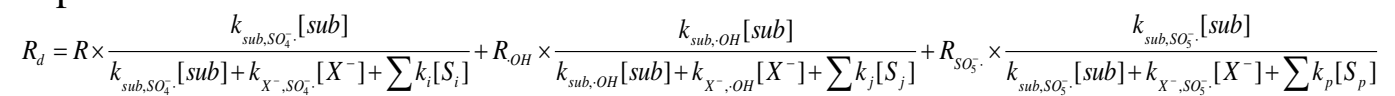

Here, $\mathrm{R}_{\mathrm{d}}$ denotes the degradation rate of $\mathrm{OII}$ and $\mathrm{R}_{\mathrm{SO}_{4 \cdot-}}$ denotes the formation rate of $\mathrm{SO}_{4}{ }^{-}$in the reaction. $\mathrm{k}_{\mathrm{sub}, \mathrm{SO}_{4--},}, \mathrm{k}_{\mathrm{sub}, \cdot \mathrm{OH}}$, and $\mathrm{k}_{\mathrm{sub}, \mathrm{SO}_{\text {s.- }}}$ are the degradation apparent rate constants in the substrate. $\mathrm{K}$ is the reaction apparent rate constant of the halogen ions. $\sum \mathrm{k}_{\mathrm{i}}\left[\mathrm{S}_{\mathrm{i}}\right]$ represents the pseudo-first-order reaction rate for $\mathrm{SO}_{4}{ }^{-}$with impurities in the solution.

$344 \mathrm{SO}_{3} \cdot{ }^{-}$in the solution is rapidly oxidized by $\mathrm{O}_{2}$ into $\mathrm{SO}_{5}{ }^{-}$, the oxidation of which is quite weak. Moreover, it is difficult to oxidize the halogen ions. Although the oxidation effect of $\mathrm{SO}_{3} \cdot{ }^{-}$on $\mathrm{OII}$ could be ignored, equation (6) may be reversed to obtain the following form:

$$
\frac{1}{R_{d}}=a+b\left[X^{-}\right]
$$

349 It is clear that $1 / R_{d}$ has a linear relationship with $\left[X^{-}\right]$. The fitting results were 350 presented in Fig. 8 (a)-(c).

351 As depicted in Fig. 8 (a) - (c), the degradation rate of OII decreased rapidly with the 352 increase in the halogen ion concentration. The degradation rate of OII decreased to $3530.053 \mathrm{~L} / \mathrm{mol} \cdot \mathrm{s}$ when the concentration of $\mathrm{I}^{-}$in the solution was increased to 2.0 $354 \mathrm{mmol} / \mathrm{L}$. When the concentration of $\mathrm{Br}^{-}$in the solution was increased to $10 \mathrm{mmol} / \mathrm{L}$, 355 the degradation rate of $\mathrm{OII}$ decreased to $0.113 \mathrm{~L} / \mathrm{mol} \cdot \mathrm{s}$. When the concentration of $\mathrm{Cl}^{-}$ 356 in the solution was increased to $1.0 \mathrm{~mol} / \mathrm{L}$, the degradation rate of OII decreased to $3570.112 \mathrm{~L} / \mathrm{mol} \cdot \mathrm{s}$. According to these data, it could be concluded that halogen ions 
exerted an evident inhibition effect on the OII degradation by the NZVI@ACC/PMS system, and the inhibition effect followed the order: $\mathrm{I}^{-}>\mathrm{Br}^{-}>\mathrm{Cl}^{-}$.

Since the addition of the halogen ions reduced the OII degradation efficiency of the NZVI@ACC/PMS system, it was inferred that in the NZVI@ACC/PMS OII degradation system, halogen ions competed for active radicals with the substrates and degradation intermediates, for electron transfer with $\mathrm{SO}_{4}{ }^{-}, \cdot \mathrm{OH}, \mathrm{SO}_{5} \cdot{ }^{-}$, and $\mathrm{SO} \cdot{ }^{-}$, and for other active radicals, resulting in the formation of less active radicals.

Owing to the variety of dyes available and the complexity of the actual dye composition, the degradation experiments were conducted using different cationic and anion dyes to evaluate the treatment effect of the NZVIA@ACC/PMS system. The results were presented in Fig. 8 (d). The rates of degradation of CR, OII, RB, and MB at $100 \mathrm{mg} / \mathrm{L}$ achieved by the optimal dosage of the NZVI@ACC/PMS system within 14 min were $99.39 \%, 98.32 \%, 64.61 \%$, and $52.55 \%$ under, respectively. It could be observed that the removal rate achieved by the NZVI@ACC/PMS system for anionic dyes was significantly higher than that achieved by this system for cationic dyes, which might be because the anionic dyes assisted NZVI@ ACC in generating $\mathrm{Fe}^{2+}$ and promoting the generation of active free radicals such as $\mathrm{SO}_{4}{ }^{\circ}$.

\section{Conclusions}

NZVI@ACC was successfully synthesized, and it was revealed that NZVI combined with ACC through coordination bonding, thereby forming a stable structure. NZVI@ACC exhibited high efficiency in activating PMS to degrade OII. The rate of OII degradation (100 mg/L) achieved using the NZVI@ACC/PMS system reached 98.32\% within $14 \mathrm{~min}$. The reaction system produced a mass of $\mathrm{SO}_{4}{ }^{-}$, which attacked the $12(\mathrm{~N})$ of OII, thereby destroying and degrading the structure of OII. Since the NZVI@ACC used in the present study was prepared using ACC from Chaohu cyanobacteria and NZVI, it allows realizing the effective utilization of the cyanobacteria reserves and NZVI.

\section{Authors' contributions:}

Jun Chen: validation, investigation, visualization, resources, writing, review \& editing. Layun Zhu: investigation, methodology, visualization, writing-original draft, writingreview \& editing.

Sisi Cao: validation, visualization, investigation, review \& editing. 
391 Zhaoming Chen: investigation, review \& editing.

392 Zihui Song: investigation, review \& editing.

393 Xiaohong Yang: investigation, review \& editing.

394 Jie Jin: validation, resources, writing, review \& editing.

395 Funding: This research was supported by the National Key R\&D Program of China 396 (2020YFC1908601, 2020YFC1908602). Science Development Fund Project of Hefei 397 University (22040521004).

398 Data availability: The datasets used and/or analyzed during the current study are 399 available from the corresponding author on reasonable request.

400 Compliance with ethical standards:

401 Ethics approval and consent to participate: Not applicable.

402 Consent for publication: Not applicable.

403 Competing interest: The authors declare that they have no competing interest.

404

405 References

406 Anipsitakis, G.P., \& Dionysiou, D.D. (2004). Radical generation by the interaction of 407 transition metals with common oxidants. Environmental Science \& Technology, $408 \quad 38(13), 3705-3712$.

409 Czech, B., Oleszczuk, P., Wiacke A.E., \& Barczak, M. (2015). Water treatment by $410 \quad \mathrm{H}_{2} \mathrm{O}_{2}$ and /or UV affects carbon nanotube (CNT) properties and fate in water and 411 tanic acid solution. Environmental Science and Pollution Research, 22(24), $412 \quad$ 20198-20206.

413 Du, J., Bao, J., Lu, C., \& Werner, D. (2016). Reductive sequestration of chromate by 414 hierarchical FeS@Fe(0) particles. Water Research, 102, 73-81.

415 Dong, Z.Y., Zhang, Q., Chen, B.Y., \& Hong, J.M. (2019). Oxidation of bisphenol A 416 by persulfate via $\mathrm{Fe}_{3} \mathrm{O}_{4}-\alpha-\mathrm{MnO}_{2}$ nanoflower-like catalyst: Mechanism and 417 efficiency. Chemical Engineering Journal, 357, 337-347.

418 Fuller, S.J., Stewart, D.I., \& Burke, I.T. (2013). Chromate reduction in highly alkaline 419 groundwater by zerovalent iron: Implications for its use in a permrable reactive 420 barrier. Industrial \& Engineering Chemistry Research, 52(13), 4704-4714.

421 Gong, Y., Li, D., Luo, C., Fu, Q., \& Pan, C. (2017). Highly porous graphitic biomass 422 carbon as advanced electrode materials for supercapacitors. Green Chemistry, $423 \quad 19(17), 4132-4140$. 
Gao, J., Han, D., Xu, Y., Liu, Y., \& Shang, J. (2019). Persulfate activation by sulfidemodified nanoscale iron supported by biochar (S-nZVI/BC) for degradation of ciprofloxacin. Separation and Purification Technology, 235, 116202.

Hori, H., Yamamoto, A., Hayakawa, E., Taniyasu, S., Yamashita, A., Kutsuna, S., Kiatagawa, H., Arakawa, R. (2005). Efficient decomposition of environmentally persistent perfluorocarboxyfic acids by use of persulfate as a photochemical oxidant. Environmental Science \& Technology, 39(7), 2383-2388.

Hussain, I., Li, M., Zhang, Y., Li, Y., Huang, S., Du, X., Liu, G., Hayat, W., Anwar, N. (2017). Insights into the mechanism of persulfate activationwith nZVI/BC nanocomposite for the degration of nonylphenol. Chemical Engineering Journal, 311, 163-172.

Huang, Z.F., Bao, H.W., Yao, Y.Y., \& Lu, W.Y. (2014). Novel green activation processes and mechanism of peroxymonosulfate based on supported cobalt phthalocyanine catalyst. Applied Catalysis B: Environmental, 154-155, 36-43.

Kwon, M., Kim, S., Yoon, Y., Jung, Y., Hwang, T.M., Lee, J., Kang, J.W. (2015). Comparative evaluation of ibuprofen removal by $\mathrm{UV} / \mathrm{H}_{2} \mathrm{O}_{2}$ and $\mathrm{UV} / \mathrm{S}_{2} \mathrm{O}_{8}{ }^{2-}$ processes for wastewater treatment. Chemical Engineering Journal, 269, 379-390.

Lin, Y.T., Liang, C., \& Chen, J.H. (2011). Feasibility study of ultraviolet activated persulfate oxidation of phenol. Chemosphere, 82(8), 1168-1172.

Li, Z., Sun, Y., Yang, Y., Han, Y., \& Tsang, D. (2019). Biochar-supported nanoscale zero-valent iron as an efficient catalyst for organic degradation in groundwater. Journal of Hazardous Materials, 383,121240.

Lee, J., Gunten, U., \& Kim, J.H. (2020). Persulfate-based advanced oxidation: critical assessment of opportunities and roadblocks. Environmental Science \& Technology,54, 3064-3081.

Lian, Y., Han, B., Liu, D.,Wang, Y., \& Du, Y. (2020). Solvent-free synthesis of ultrafine tungsten carbide nanoparticles-decorated carbon nanosheets for microwave absorption. Nano-Micro Letters, 12(1), 153-166.

Liu, C., Wang, Y., Zhang, Y.P., Zhang, Y.T., Li, R.Y., Meng, W.D., Song, Z.L., Qi, F., Xu, B.B., Chu, W., Yuan, D.H. (2018). Enhancement of Fe@ porous carbon to be an efficient mediator for peroxymonosulfate activation for oxidation of organic contaminants: Incorporation $\mathrm{NH}_{2}$-group into structure of its $\mathrm{MOF}$ precursor. Chemical Engineering Journal, 354, 835-848. 
Li, X.N., Wang, Z.H., Zhang, B., Rykov, A.I., Athemed, M.A., \& Wang, J.H. (2016). $\mathrm{FexCo}_{3}-\mathrm{xO}_{4}$ nanocages derived from nanoscale metal-organic frameworks for removal of bisphenol A by activation of peroxymonosulfate. Applied Catalysis B: Environmental, 181, 788-799.

Lin, C.C., Lee, Li. T., \& Hsu, L.J. (2013). Performance of $\mathrm{UV} / \mathrm{S}_{2} \mathrm{O}_{8}{ }^{2-}$ process in degradating polyvinyl alcohol in aqueous solutions. Journal of Photochemistry and Photobiology A: Chemistry, 252(1), 1-7.

Ma, W., Wang, N., Tong, T., Zhang, L., Lin, K., Han, X., \& Du, Y. (2018). Nitrogen, phosphorus, and sulfur tri-doped hollow carbon shells derived from ZIF$67 @$ poly (cyclotriphosphazene-co-4,4'-sulfonyldiphenol) as a robust catalyst of peroxymonosulfate activation for degradation of bisphenol A. Carbon, 137, 291303.

Pham, H.T., Suto, K., \& Inoue, C. (2009). Trichloroethylene transformation in aerobic pyrite suspension: pathways and kinetic modeling. Environmental Science \& Technology, 43(17), 6744-6749.

Sun, Y., Cho, D.W., Graham, N., Hou, D., Yip, A., \& Khan, E. (2019). Degradation of antibiotics by modified vacuum-UV based processes: Mechanistic consequences of $\mathrm{H}_{2} \mathrm{O}_{2}$ and $\mathrm{K}_{2} \mathrm{~S}_{2} \mathrm{O}_{8}$ in the presence of halide ions. Science of the Total Environment, 664, 312-321.

Sun, Y.M., Song, H., Ma, W.J., Yu, B.Y., \& Hu, J.L. (2017). Advanced treatment of penicillin wastewater using Fenton oxidation method. Fine and Specialty Chemical, 25(2), 23-27.

Soubh, A., \& Mokhtarani, N. (2016). The post treatment of composting leachate with a combination of ozone and persulfate oxidation processes. RSC Advances, 6(80), 1-22 .

Song, S.J., Ma, F.W., Wu, G., Ma, D., Geng, W.D., \& Wan, J.F. (2015). Facile selftemplate large scale preparation of biomass-derived 3D hierarchical porous carbon for advanced supercapacitors. Journal of Material Chemistry, 3(35), $18154-18162.13$

Tsai, T.T., Kao, C.M., Yeh, T.Y., \& Lee, M.S. (2008). Chemical Oxidation of Chlorinated Solvents in Contaminated Groundwater: Review. Practice Periodical of Hazardous Toxic \& Radioactive Waste Management, 12(2), 116-126. 
489

490

491

492

493

494

495

496

497

498

499

500

501

502

503

504

505

506

507

508

509

510

511

512

513

514

515

516

517

518

519

520

521

Wang, D. Z., Jiang, H.M. (2017). Removing the chroma of dye wastewater by Fenton reagent oxidation process. Industrial Catalysis, 25(11), 82-84.

Wu, Y., Chen, Y., Wang, H., Wang, C., Wang, A., Shuai, Z.,Li, X., Sun, D., Jiang, J. (2018). Efficient ORR electrocatalytic activity of peanut shell-based graphitic carbon microstructures. Journal of Material Chemistry, 6, 12018-12028.

Xu, J., Avellan, A., Li, H., Liu, X., \& Lowry, G. V. (2020). Sulfur loading and speciation control the hydrophobicity, electron transfer, reactivity, and selectivity of sulfidized nanoscale zerovalent iron. Advanced Materials, 32, 201906910.

Yang, S.Y., Yang, X., Shao, X.T., Niu, R., \& Wang, L.L. (2011). Activated carbon catalyzed persulfate oxidation of azo dye acid orange 7 at ambient temperature. Journal of Hazardous Materials, 186(1), 659-666.

Yan, J.C., Chen, M.F., Gao, W.G., Xue, S., \& Han, L. (2015). Biochar supported nanoscale zerovalent iron composite used as persulfate activator for removing trichloroethylene. Bioresource Technology, 175, 269-274.

Yin R, Guo W, Du J, Zhou, X., Zheng, H., Wu, Q., Chang, J., Ren, N. (2017). Heteroatoms doped graphene for catalytic ozonation of sulfamethoxazole by metal-free catalysis: Performances and mechanisms. Chemical Engineering Journal, 317, 632-639.

Zha, F.G., Yao, D.X., Hu, Y.B., Gao, L.M., \& Wang, X.M. (2016). Integration of $\mathrm{US} / \mathrm{Fe}^{2+}$ and photo-Fenton in sequencing for degradation of landfill leachate. Water Science \& Technology, 73(2), 260-266.

Zhong, Y., Pan, Z., Wang, X., Yang, J., \& Li, W. (2019). Hierarchical $\mathrm{Co}_{3} \mathrm{O}_{4}$ nanomicro arrays featuring superior activity as cathode in a flexible and rechargeable zinc-air battery. Advanced Science, 6(11), 1802243.

Zhou, D., Zhang, C.B., Yu, Y.T., Li, Z., Wu, F., \& Chen, L. (2014). A novel photochemical system of ferrous sulfite complex: Kinetics and mechanisms of rapid decolorization of acid orange 7 in aqueous solutions. Water Research,57, 87-95.

Zhang, M., Xiao, C.M., Zhang, C., Qi, J.W., \& Li, J.S. (2020). Large-scale synthesis of biomass@mof-derived porous carbon/cobalt nanofiber for environmental remediation by advanced oxidation processes. ACS EST Engineering, 1, 249-260.

Zrinyi, N., \& Pham, L.T. (2017). Oxidation of benzoic acid by heat-activated persulfate: Effect of temperature on transformation pathway and product 
distribution. Water Research, 120, 43-51.

523 Zhang, T.T., Yang, Y.L., Gao, J.F., Li, X., Yu, H.K., Wang, N., Du, P., Yu, R., Li, H., 524 Fan, X.Y., Zhou, Z.W. (2020). Synergistic degradation of chloramphenicol by 525 ultrasound-enhanced nanoscale zero-valent iron/persulfate treatment. Separation 526 and Purification Technology, 240, 116575.

527 Zhang, K., \& Parker, K.M. (2018). Halogen radical oxidants in natural and engineered 528 aquatic systems. Environmental Science \& Technology, 52 (17), 9579-9594. 
Figures
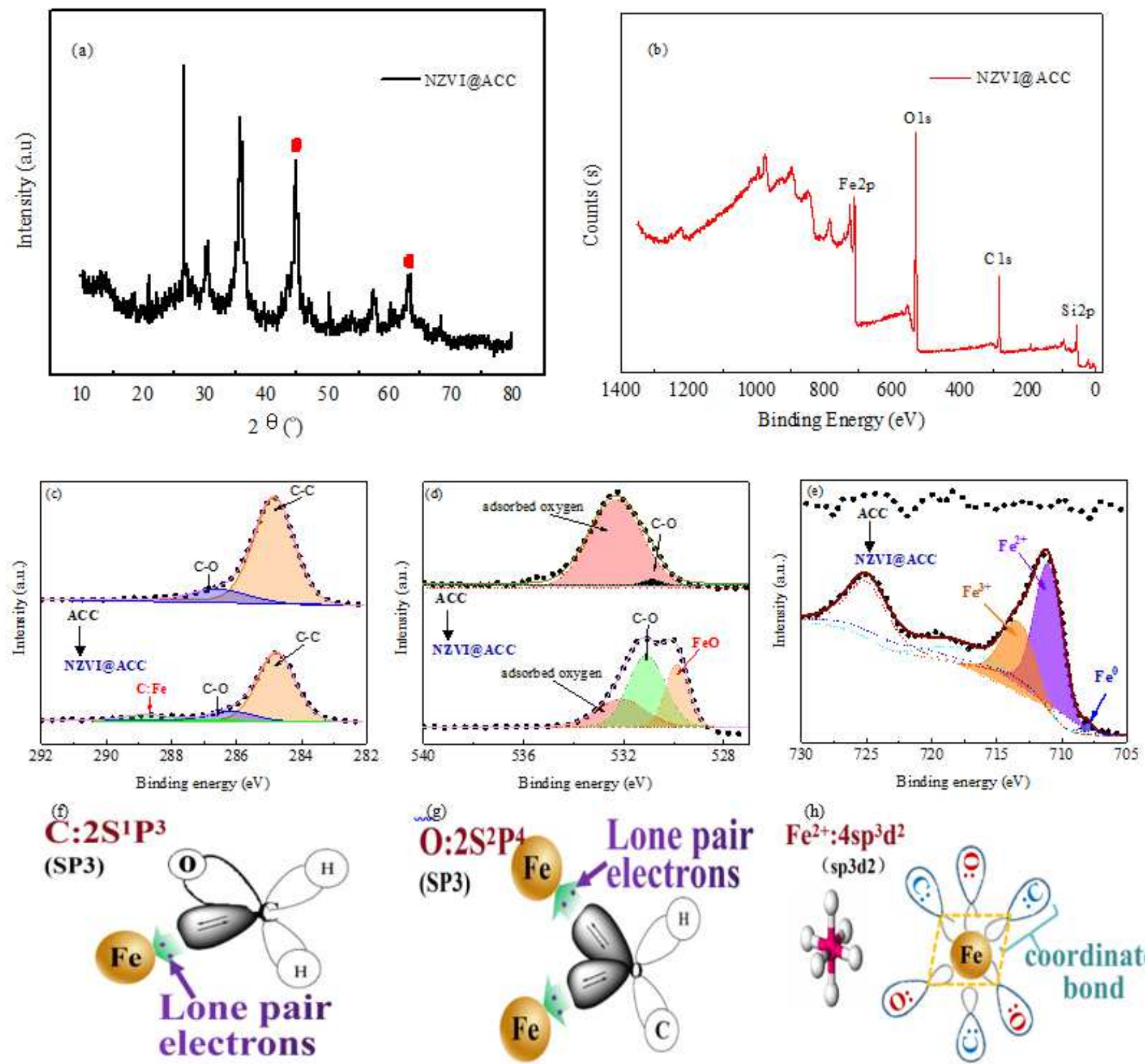

(h)

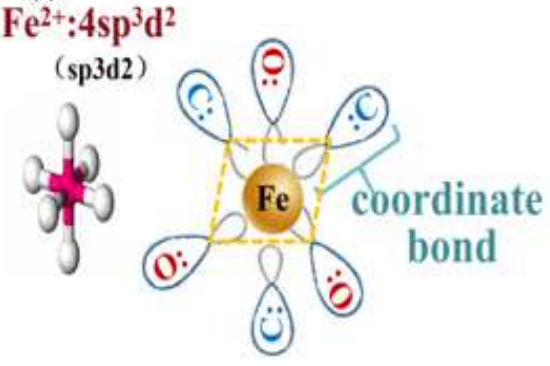

Figure 1

(a) XRD pattern; (b) XPS survey; (c, d, e) Comparative XPS analysis of the C 1s, 0 1s, and Fe 2p binding states; and $(f, g, h)$ the mechanism underlying the formation of coordinated bonds in NZVI@ACC. 

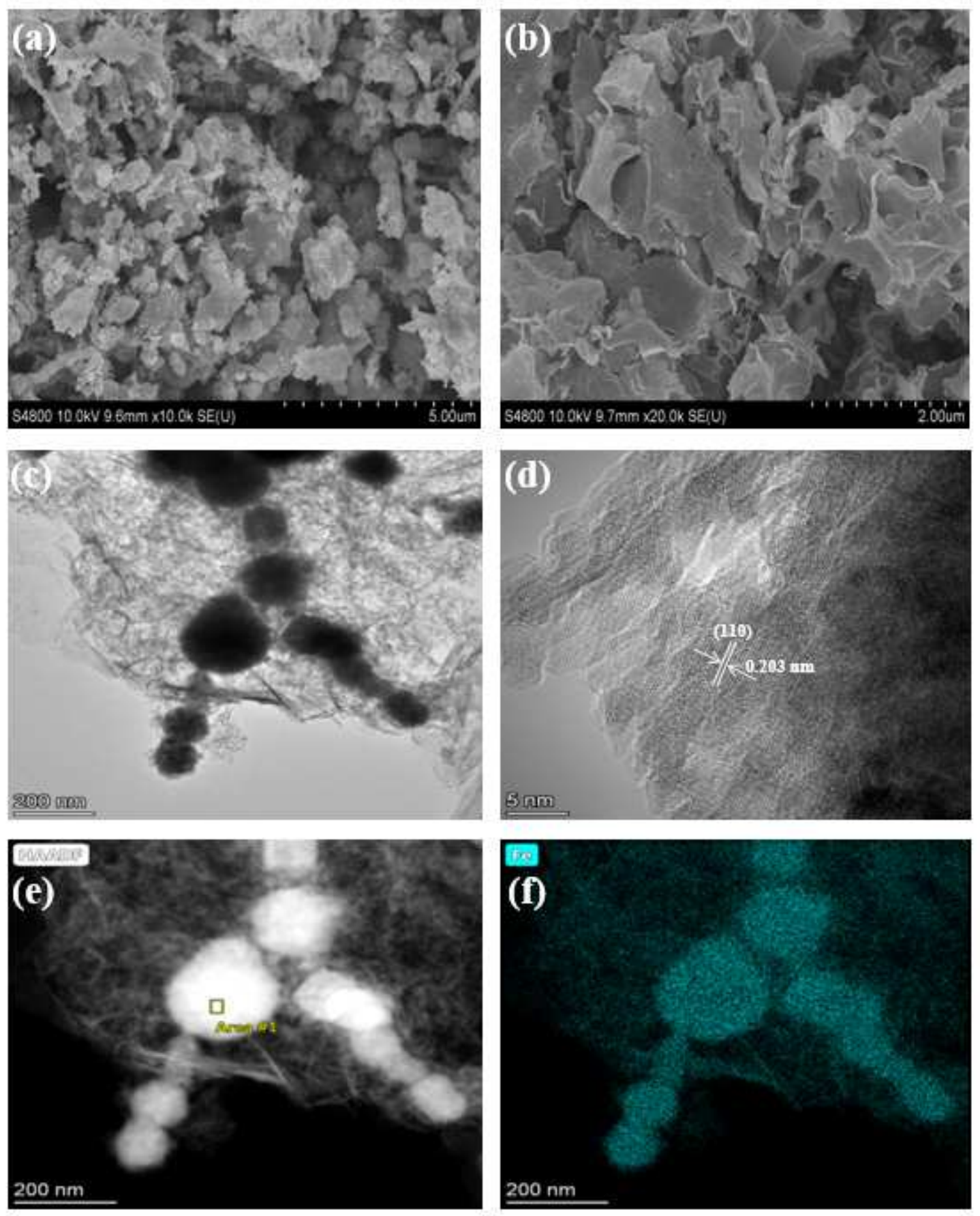

Figure 2

(a, b) SEM; (c, d) TEM; and (e, f) TEM mapping of NZVI@ACC. 

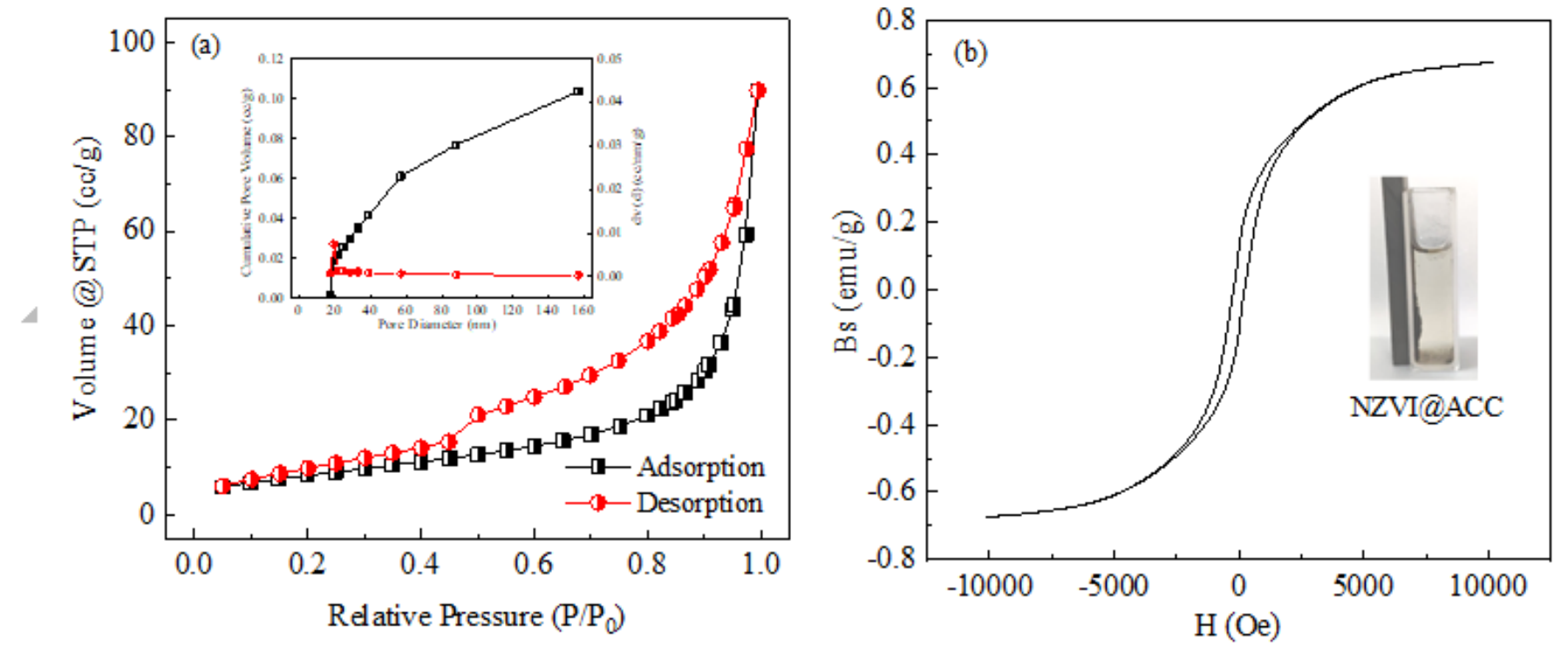

Figure 3

(a) $\mathrm{N}_{2}$ adsorption-desorption isotherm, and BJH desorption pore size distribution; (b) hysteresis loop of NZVI@ACC, and separation of NZVI@ACC from solution. 

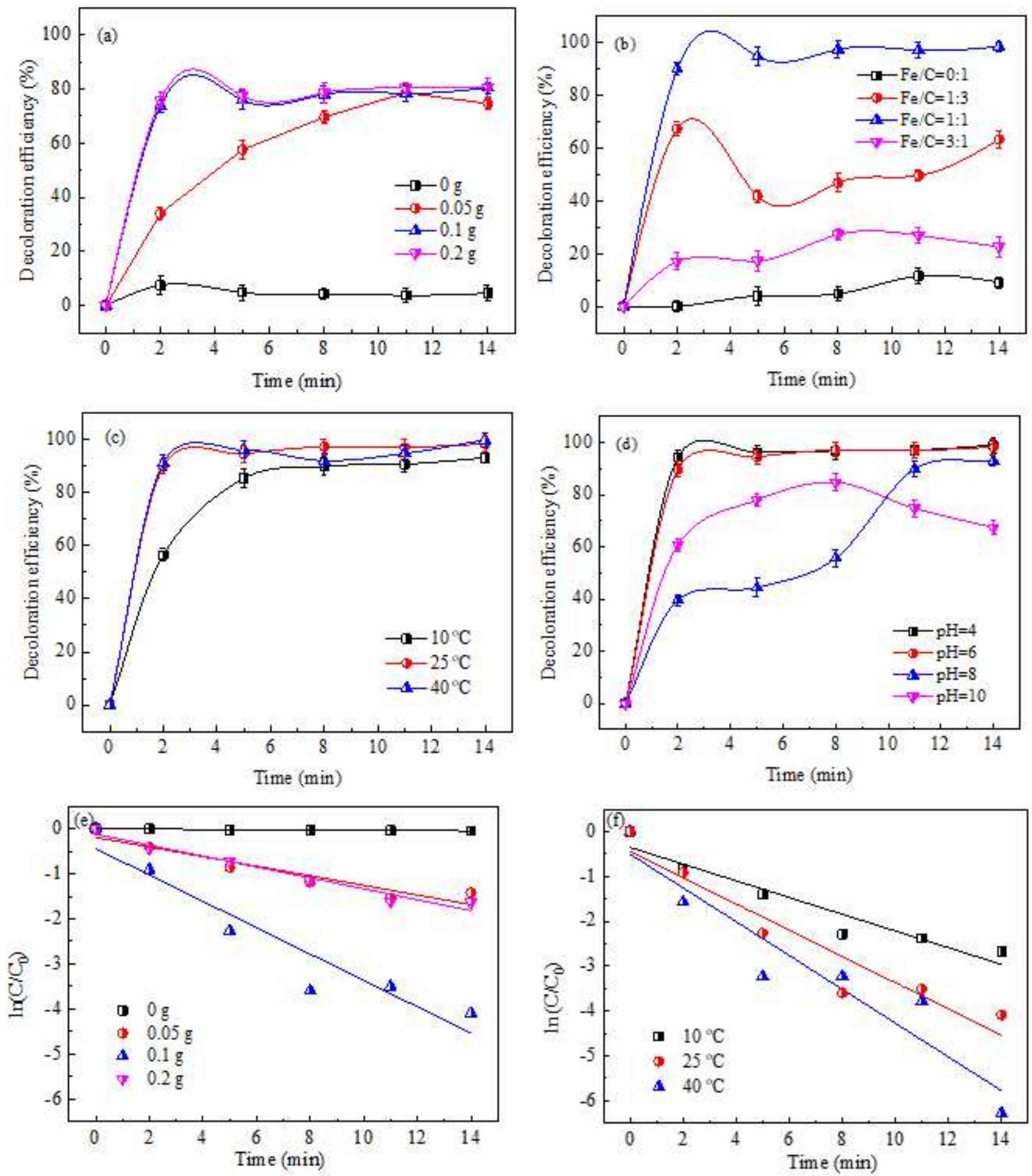

Figure 4

Effect of (a) activator dosage, (b) Fe/ $\mathrm{C}$ ratio, (c) reaction temperature, (d) initial $\mathrm{pH}$, and kinetic simulation of (e) activator dosage and (f) reaction temperature on Oll degradation. 

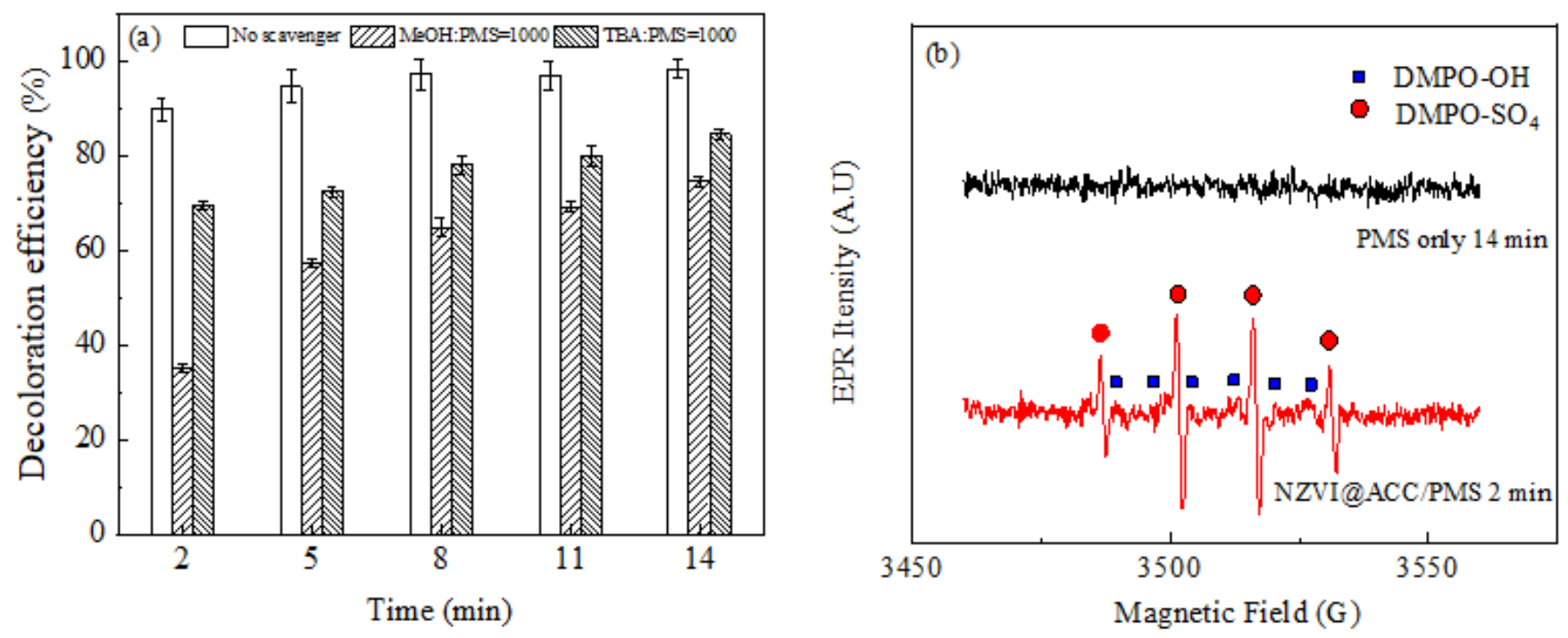

Figure 5

(a) Effects of inhibitors on Oll degradation; (b) EPR spectra for DMPO of PMS and NZVI@ACC/PMS.

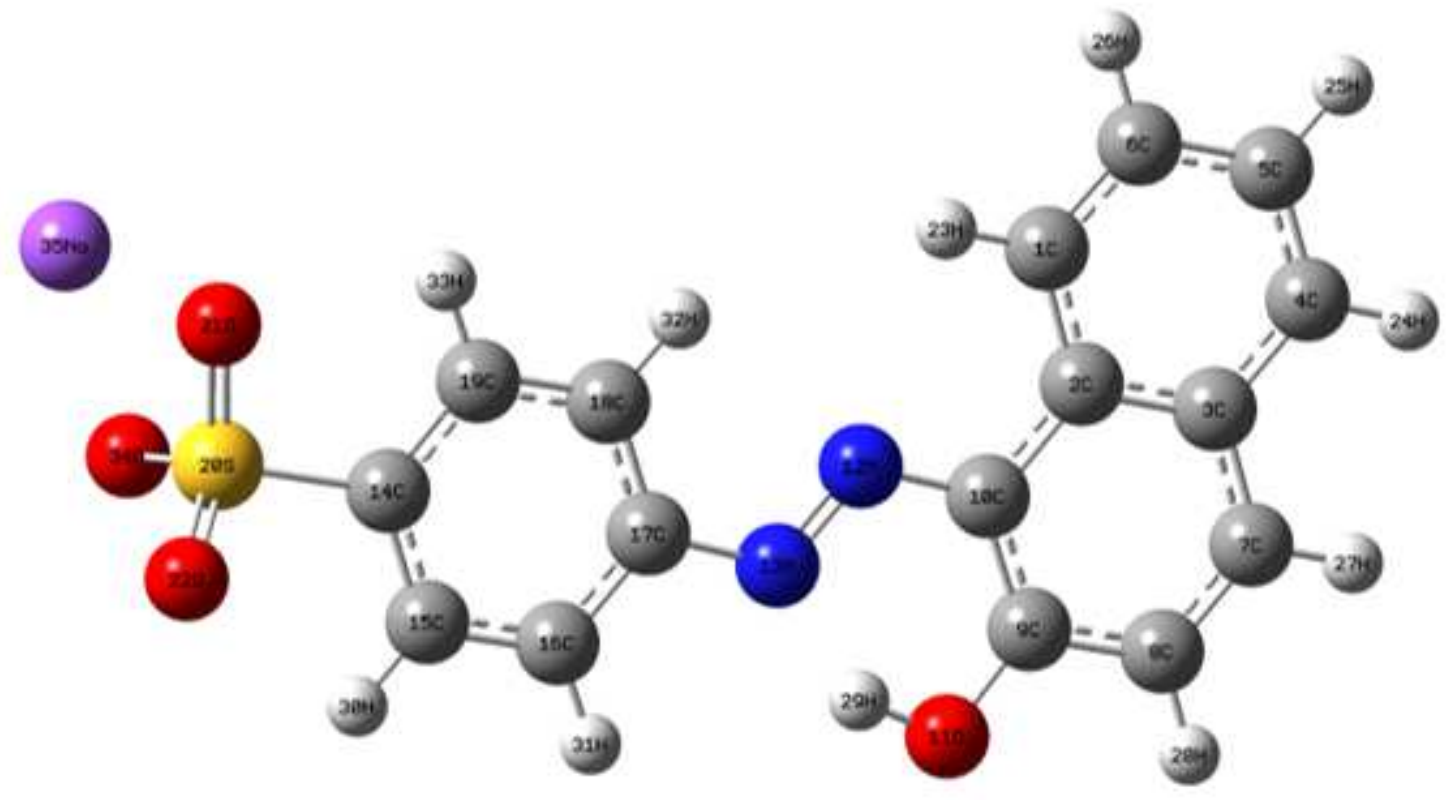

Figure 6

Optimized structure of Oll and the numbering system (gray: carbon; red:

oxygen; blue: nitrogen; white: hydrogen; yellow: sulfur; and purple: sodium). 


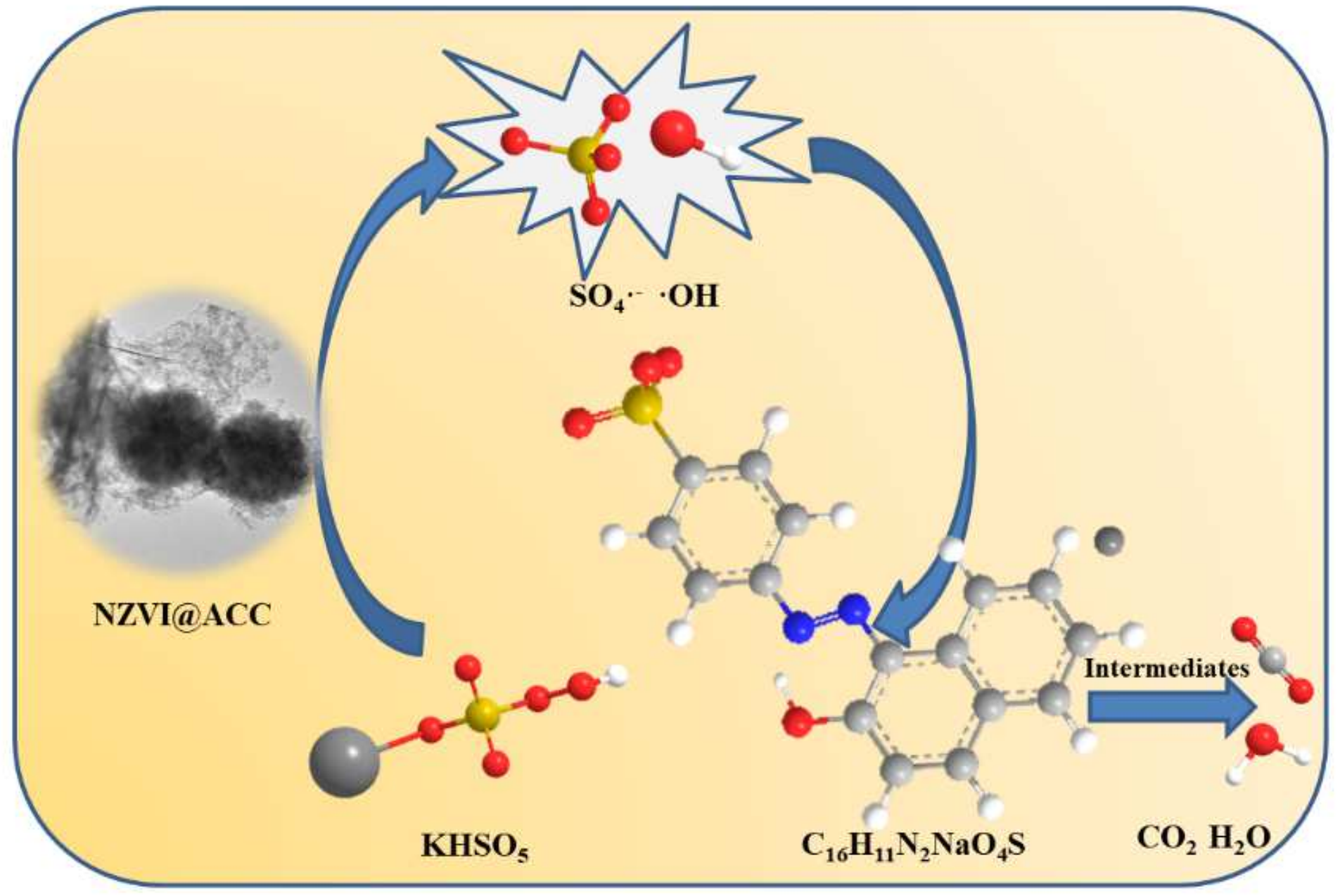

Figure 7

The proposed mechanism underlying the reaction for OII degradation by NZVI@ACC/PMS. 

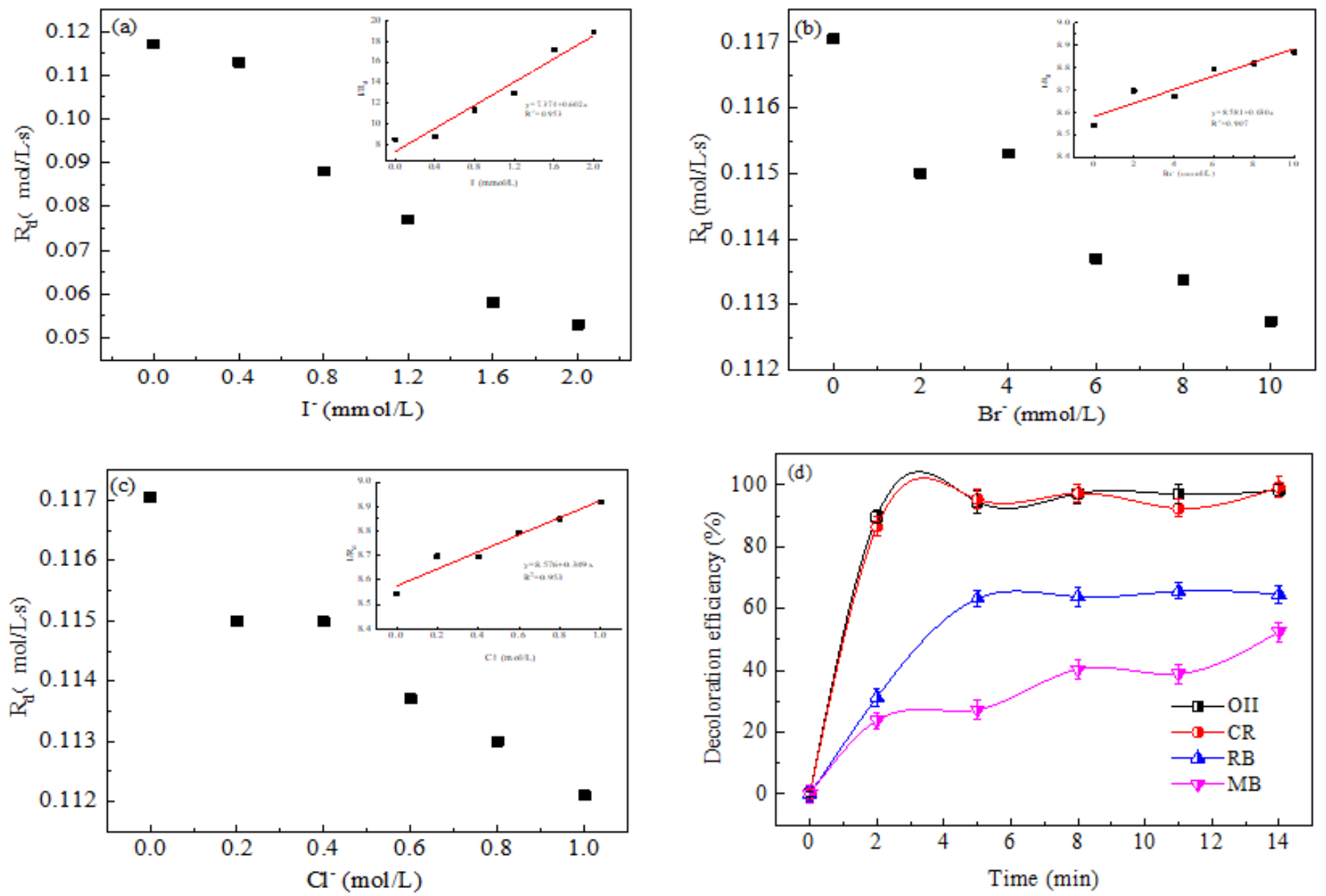

Figure 8

Effect of the NZVI@ACC/PMS system on different $(a, b, c)$ halogens and (d) dyes. 